\title{
Spinal Deformity in Neurofibromatosis: Classification and Management
}

\section{Young Seop Park and Seung-Jae Hyun *}

Department of Neurosurgery, Spine Center, Seoul National University Bundang Hospital, Seoul National University College of Medicine, Seongnam, Gyeonggi, Korea *Corresponding author: Seung-Jae Hyun, Department of Neurosurgery, Spine Center, Seoul National University Bundang Hospital, Seoul National University College of Medicine, 300 Gumi-dong, Bundang-gu, Seongnam-si, Gyeonggi-do 463-707, Korea, Tel: +82-31-787-7164; Fax: +82-31-787-4059; E-mail: neurospine@snubh.org, sjhyun@snubh.cu.cc

Rec date: Sep 01, 2014, Acc date: Oct 21, 2014, Pub date: Oct 23, 2014

Copyright: (c) 2014 Park YS, et al. This is an open-access article distributed under the terms of the Creative Commons Attribution License, which permits unrestricted use, distribution, and reproduction in any medium, provided the original author and source are credited.

\section{Abstract}

The effects of treatment of scoliosis in neurofibromatosis type 1 are less satisfactory than other scoliotic types due to the particular pathogenesis and clinical characteristics. Surgical treatment usually included 360 degrees fusion with instrumentation, but optimal strategies are different according to the degree of deformity. High incidence of pseudarthrosis, extensive bleeding and curve progression even after solid spinal fusion are also major concerns of neurofibromatosis type 1 associated spinal deformity surgery. With advance of technology, cobalt-chrome rod with dural rod technique, tranexamic acid, recombinant human bone morphogenetic protein-2 and electrophysiologic monitoring were used in neurofibromatosis deformity surgery to get better outcome. Searching from PubMed, we reviewed overall about neurofibromatosis spine deformity surgery.
\end{abstract}

Keywords: Neurofibromatosis; Scoliosis; Kyphosis; Deformity

\section{Introduction}

Neurofibromatosis (NF) type 1, peripheral neurofibromatosis, having a global prevalence of one in 3000 individuals and published reports of prevalence of scoliosis varied from $10 \%$ to $30 \%$ during childhood [1-5]. Spinal deformity is the most common osseous complication of NF-1 and many of these patients will eventually require surgery for curve progression [6-9]. Further, several studies also report poor bone quality of dystrophic change with decreased bone mineral density $[10,11]$. In this paper, we reviewed almost all paper from PubMed search, from management methods of the NF spinal deformity to additional strategies to overcome this challenging disease.

\section{Search Strategy and Selection Criteria}

We searched PubMed (September 1, 1965 to September 1, 2015) using the search term 'neurofibromatosis' with 'deformity, scoliosis, and kyphosis'. Publications were reviewed and selected predominately from the last 10 years. Greater emphasis was placed on selecting high quality research and review articles published in the last 10 years. Reference lists of articles identified by this search strategy were reviewed and our reference list was also modified on the basis of comments from Corresponding Author to ensure no significant publications were missed.

\section{Classification of Spinal Deformity}

Coronal spinal decompensation is classified into non-dystrophic and dystrophic types based on the absence or presence of skeletal dysplasia [12]. Characterization of the curve should be based on a combination of MRI and radiological findings [13-16]. Clinical and radiologic findings, treatment, and complications of non-dystrophic type are similar to idiopathic scoliosis [2,17-20]. However, patients with NF-1 associated non-dystrophic scoliosis are historically affected earlier in life, have a worse prognosis, and have a higher pseudarthrosis rate or failure to obtain spinal fusion after surgery than their idiopathic counterparts [2,18]. Vertebral scalloping, rib penciling, spindling of the transverse processes and wedging of vertebral bodies, paraspinal or intraspinal soft tissue masses, a short curve with significant apical rotation are typical feature of dysplastic type $[12,21]$. These could lead to subluxation or dislocation of vertebral bodies [22]. Dystrophic changes are thought to be intrinsic in origin or associated with intraspinal anomalies, such as dumbbell shape neurofibromas causing foraminal enlargement, dural ectasia causing posterior vertebral scalloping and lateral thoracic meningocele [13-16,20]. Anterior and lateral scalloping was commonly the result of primary mesodermal dysplasia [16]. Even in tremendous angular deformity, if dural ectasia (Figure 1) is the reason of canal expansion, it may not be accompanied by spinal cord compromise and neurologic deficit [23]. On the other hand, if an intraspinal neurofibroma is related to the development of canal widening, it can provoke cord compression easily [23]. Generally, the more severe the dystrophic changes identified, the higher the likelihood that the scoliotic curvature will find out. When a combination of three or more dysplastic features was present in NF-1, the risk of curve progression was significantly increased in $85 \%$ of the patients, while rib pencilling was the only singular dystrophic factor statistically influencing risk of scoliosis deterioration [24].

\section{Radiological Evaluation}

Postero-anterior and lateral radiographs of the entire spine should be obtained in all NF-1 patients. If there is any suspicion of instability, computed tomography (CT) and/or flexion-extension plain radiographs are indicated. The dynamic or supine radiographs are helpful to evaluate flexibility of the curve. Magnetic resonance imaging (MRI) of the entire spine will illustrate the intraspinal and extraspinal contents that might interfere with any attempt for surgical correction of the deformity [13-16]. A thorough search for evidence of dysplastic changes on plain radiograph and MRI is essential and will clarify prognosis and management options even if there were no neurologic 
Page 2 of 5

deficit $[2,5,9]$. MRI is also helpful to find out spinal neurofibromas, closely associated with an increased incidence of scoliosis [13-16]. In contrast, other investigators do not advocate routine MRI and emphasize that MRI should be indicated by clinical necessity $[5,14,15]$.

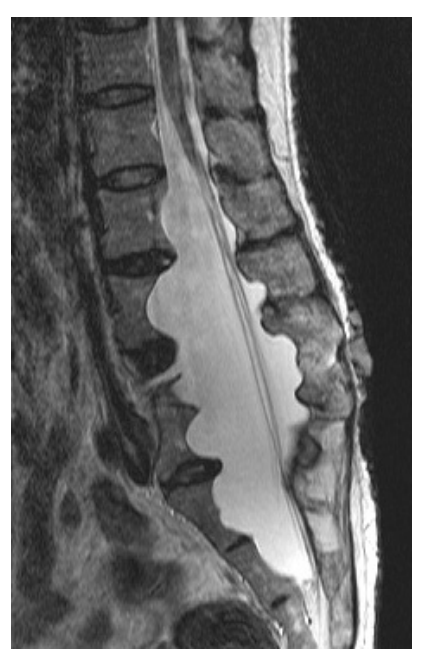

Figure 1: Dural ectasia from posterior scalloping. 54 year old female patient spine magnetic resonance imaging shows dural ectasia causing canal expansion without any neurological deficit.

\section{Non-Dystrophic Curves Management}

Non-dystrophic curves can be managed similarly to idiopathic scoliosis and shows comparable response to treatment $[2,17,18,25,26]$. If the degree of the scoliotic deformity is less than $20-25^{\circ}$, it may be observed with a regular follow up [9]. Brace can be applied for curves between $20^{\circ}$ and $40^{\circ}$ if the patient still has remaining growth. When bracing is selected as the preferred management option, compliance should be considered, because child patients with NF-1 often have cognitive dysfunction, intellectual handicap and great degree of psychological problems $[9,19,27,28]$. If the deformity exceeds $40^{\circ}$, it should be treated surgically by a posterior spinal fusion and segmental instrumentation. The use of autologous iliac crest graft is recommended to enhance a bony fusion, especially since there is evidence of a higher incidence of nonunion comparison to those with idiopathic scoliosis $[2,18,25,26]$. Circumferential fusion including discectomy and instrumentation is necessary to achieve restoration of spinal curvature in patients with deformity more than $55-60^{\circ}$ $[2,18,25,29]$.

When observing patients with NF-1 initially classified as having non- dystrophic curves over an extended period of time, there is a higher propensity for developing progressive deformity compared to the idiopathic scoliosis population $[2,18,25,12]$. Close observation of the evolution of deformity is critical due to the possibility of modulation of spinal deformity from non-dystrophic to dystrophic curves. Modulation rate of non-dystrophic to dystrophic scoliotic curvatures is outstanding to children before 7 years. Dystrophic changes may develop with growth as part of the modulation phenomenon, but does not show a consistent pattern [24].

\section{Dystrophic Curves Management}

The presence of a combination of three or more dystrophic features on radiographs and MR image was highly predictive of the need for surgery. Individual features most predictive of need for surgery were the presence of vertebral scalloping followed by the presence of dural ectasia [23]. Apart from the presence of dystrophic changes, other factors that increase substantially the risk of curve deterioration include a young age and a high magnitude of deformity at initial presentation, pathological kyphosis of greater than $50^{\circ}$, location of the apex of the curvature in the mid to caudal thoracic region of the spine, severe apical vertebral rotation of more than $11^{\circ}$, and a severely notched anterior vertebral body $[2,12,18,20,25,26,30,31]$. The dystrophic type of scoliosis is more resistant to treatment. The natural history of untreated dysplastic curves, particularly between the ages of 6 and 18 years, is that of relentless deterioration [32]. Brace therapy has been ineffective and the need for early surgery is well documented even in young children $[19,33]$. The need for early fusion for dystrophic NF spinal deformity is now a well-known and widely accepted method [2,9,17,18,20,24,25,26,31,34-41]. Early spinal fusion does not lead to loss of height since the developing curves limit the growth potential [9]. Dystrophic scoliotic curves less than $20^{\circ}$ should be closely observed with short intervals to identify sudden and rapid progression [6]. For patients with $20-40^{\circ}$ scoliosis with less than $50^{\circ}$ of kyphosis, posterior spinal arthrodesis using segmental fixation with either multiple sublaminar wires or dual rod-multiple hook constructs and the application of plentiful bone graft is strongly indicated [2]. Apart from this selective group of patients that can be treated with isolated posterior instrumented fusion, for most dystrophic NF spine, corpectomy and circumferential fusion shows high fusion rate, good curve correction, and good functional outcome [36,42-45]. Most authors recommend circumferential fusion and instrumentation as the most reliable surgical option in patients of thoracic kyphosis that exceeds $50^{\circ}[26,46,47]$. Structural auto bone graft, rib or fibula, could reinforce the vertebral column followed by posterior instrumentation with copious amount of autologous iliac crest bone [38,42].

Kyphosis, by creating a pathological spinal flexion, produces excessive attenuation and deformation of the spinal cord parenchyma and gives rise to neurological symptoms more easily than scoliosis [48-51]. If the cord is compressed due to the development of a progressive kyphotic deformity, treatment should consist of anterior decompression through a vertebrectomy in the concavity of the deformity followed by combined anterior and posterior fusion with instrumentation [38,42]. Laminectomy has been shown to be ineffective to release pressure in a sharply angulated spinal cord [38]. In the presence of an angular kyphotic deformity, if it is flexible on dynamic plain radiographs, with associated mild neurologic involvement, preoperative halo-dependent traction may be considered, in order to maximize curve correction during the anterior decompression and facilitate placement of the strut graft [37]. The development of thoracic lordosis is relatively infrequent in patients with NF-1. However, it is often associated with significant respiratory compromise and mitral valve prolapse [52].

\section{Strategies for NF-1 Spinal Deformity Surgery}

Primary goal of NF deformity surgery is to stabilize the vertebral column and halt further progression of the deformity rather than perform perfect correction that could result to permanent neurologic sequelae [9]. During the posterior exposure of the spine, the surgeon should be particularly careful to avoid invading the spinal canal and 
injuring the cord in areas where the posterior bony elements are weakened (Figure 2) due to the presence of intraspinal tumors or dural ectasia [9].

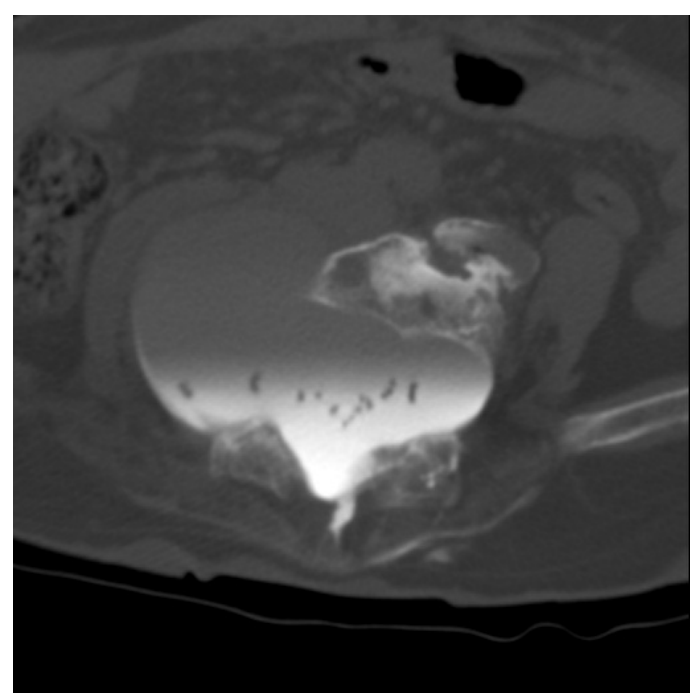

Figure 2: Weakened posterior body element from dural ectasia. Spinal computerized tomographic scan with myelogram shows weakened posterior bony elements due to the presence of dural ectasia.

If excessive angular kyphosis is present or if the vertebrae are weak due to the bony dysplasia, postoperative orthotic immobilization is recommended even if instrumentation has been successfully applied, in order to remove excessive strains at the proximal hook sites and prevent dislodgement of the instruments [2,26]. Moreover, because the pedicles were too hypoplastic (Figure 3) to install pedicle screws, obtaining adequate fixation points was very important.

Patients with type-1 NF are known to be osteopenic, predisposes the instrumentation construct to screw pullout, and have high pseudarthrosis rates of up to $60 \%$ [40]. Some authors recommends posterior re-exploration and augmentation of the fusion in 6 months if there were possibility of fusion failure $[20,26,38]$. Use of recombinant human bone morphogenetic protein-2 (rhBMP-2) has been studied extensively to enhance fusion and has demonstrated equivalent or better fusion rates than autologous iliac bone graft [53]. Despite the demonstrated efficacy of rhBMP-2, there were possibility of heterotopic ossification, radiculitis and the promotion of tumor formation in animals [54,55]. Nevertheless, there is no report of rhBMP-2 induced cancer in humans yet, interaction of the rhBMP-2 with hyperproliferative neurofibroma is a potential concern, especially in young patients [56]. Both the risks and the benefits of off-label use of rhBMP-2 should be carefully considered on a case-by-case basis.

The usual reason for failure of spine surgery is inadequate anterior procedures, such as performing a short fusion or using a limited amount of bone graft. Dystrophic curves should be treated aggressively, as there is a strong tendency for curve progression even after spinal fusion [35]. All grafts should have direct contact with the spine and with each other, while any intervening soft tissue should be meticulously excised. The fusion should be extended to include the neutral vertebra above and below the curve. Segmental instrumentation can occasionally be challenging, since severely deformed vertebrae constitute poor anchorage points for fixation. If internal fixation is not technically feasible because of poor bone stock, in situ fusion with bone autograft and application of a postoperative cast or brace is necessary [7].

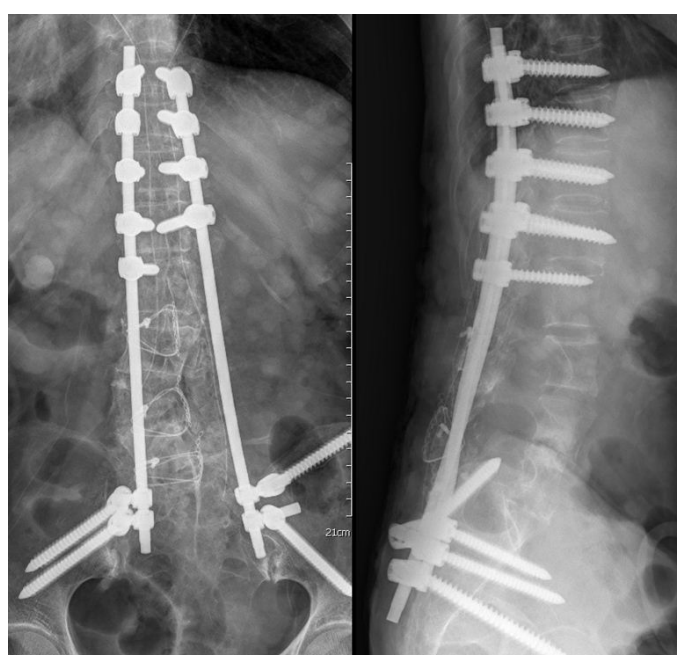

Figure 3: Iliac screw with Wisconsion wiring technique. Lumbar pedicles are too hypoplastic to install the pedicle screws, multiple iliac screws were inserted instead of lower lumbar pedicle screws with modified Wisconsin wiring technique.

Extensive bleeding is another major concern. Excessive bleeding can hamper particularly anterior approaches to the vertebral bodies for corpectomy or vertebrectomy and can occur due to rigorous bone bleeding or the presence of paraspinal neurofibromas and plexiform venous channels in the soft tissues surrounding the spine. Meticulous hemostasis and wound drainage are absolutely needed. As potent antifibrinolytics, tranexamic acid (TXA) and aminocaproic acid are helpful to decrease intraoperative and postoperative blood loss in adult as well as pediatric patients [55-57]. Low dose TXA to adults and high dose TXA to pediatric patients is recommended [57].

\section{Conclusion}

NF-1 associated spinal deformity requires early recognition and aggressive surgical intervention according degree of deformity with regular follow-up. With effort to reduce bleeding loss with TXA, surgeons should utilize modern technologies of instrumentation and consider new potent biologic materials like rhBMP-2 to get better outcome.

\section{References}

1. Jett K, Friedman JM (2010) Clinical and genetic aspects of neurofibromatosis 1. Genet Med 12: 1-11.

2. Kim HW, Weinstein SL (1997) Spine update. The management of scoliosis in neurofibromatosis. Spine (Phila Pa 1976) 22: 2770-2776.

3. Akbarnia BA, Gabriel KR, Beckman E, Chalk D (1992) Prevalence of scoliosis in neurofibromatosis. Spine (Phila Pa 1976) 17: S244-248.

4. Cnossen MH, de Goede-Bolder A, van den Broek KM, Waasdorp CM, Oranje AP, et al. (1998) A prospective 10 year follow up study of patients with neurofibromatosis type 1. Arch Dis Child 78: 408-412. 
5. Gutmann DH, Aylsworth A, Carey JC, Korf B, Marks J, et al. (1997) The diagnostic evaluation and multidisciplinary management of neurofibromatosis 1 and neurofibromatosis 2. JAMA 278: 51-57.

6. Feldman DS, Jordan C, Fonseca L (2010) Orthopaedic manifestations of neurofibromatosis type 1. J Am Acad Orthop Surg 18: 346-357.

7. Vitale MG, Guha A, Skaggs DL (2002) Orthopaedic manifestations of neurofibromatosis in children: an update. Clin Orthop Relat Res : 107-118.

8. Zhang W, Rhodes SD, Zhao L, He Y, Zhang Y, et al. (2011) Primary osteopathy of vertebrae in a neurofibromatosis type 1 murine model. Bone 48: 1378-1387.

9. Tsirikos AI, Saifuddin A, Noordeen MH (2005) Spinal deformity in neurofibromatosis type-1: diagnosis and treatment. Eur Spine J 14: 427-439.

10. Stevenson DA, Schwarz EL, Viskochil DH, Moyer-Mileur LJ, Murray M, et al. (2008) Evidence of increased bone resorption in neurofibromatosis type 1 using urinary pyridinium crosslink analysis. Pediatr Res 63: 697-701.

11. Stevenson DA, Moyer-Mileur LJ, Murray M, Slater H, Sheng X, et al. (2007) Bone mineral density in children and adolescents with neurofibromatosis type 1. J Pediatr 150: 83-88.

12. Funasaki H, Winter RB, Lonstein JB, Denis F (1994) Pathophysiology of spinal deformities in neurofibromatosis. An analysis of seventy-one patients who had curves associated with dystrophic changes. J Bone Joint Surg Am 76: 692-700.

13. Egelhoff JC, Bates DJ, Ross JS, Rothner AD, Cohen BH (1992) Spinal MR findings in neurofibromatosis types 1 and 2. AJNR Am J Neuroradiol 13: 1071-1077.

14. Khong PL, Goh WH, Wong VC, Fung CW, Ooi GC (2003) MR imaging of spinal tumors in children with neurofibromatosis 1. AJR Am J Roentgenol 180: 413-417.

15. Thakkar SD, Feigen U, Mautner VF (1999) Spinal tumours in neurofibromatosis type 1: an MRI study of frequency, multiplicity and variety. Neuroradiology 41: 625-629.

16. Tsirikos AI, Ramachandran M, Lee J, Saifuddin A (2004) Assessment of vertebral scalloping in neurofibromatosis type 1 with plain radiography and MRI. Clin Radiol 59: 1009-1017.

17. Betz RR, Iorio R, Lombardi AV, Clancy M, Steel HH (1989) Scoliosis surgery in neurofibromatosis. Clin Orthop Relat Res : 53-56.

18. Crawford AH (1989) Pitfalls of spinal deformities associated with neurofibromatosis in children. Clin Orthop Relat Res : 29-42.

19. Savini R, Parisini P, Cervellati S, Gualdrini G (1983) Surgical treatment of vertebral deformities in neurofibromatosis. Ital J Orthop Traumatol 9: 13-24.

20. Winter RB, Moe JH, Bradford DS, Lonstein JE, Pedras CV, et al. (1979) Spine deformity in neurofibromatosis. A review of one hundred and two patients. J Bone Joint Surg Am 61: 677-694.

21. Sponseller P (2003) The spine in skeletal syndromes and dysplasias: Spinal deformities. The comprehensive text. Thieme, New York.

22. Rockower S, McKay D, Nason S (1982) Dislocation of the spine in neurofibromatosis. A report of two cases. J Bone Joint Surg Am 64: 1240-1242.

23. Lykissas MG, Schorry EK, Crawford AH, Gaines S, Rieley M, et al. (2013) Does the presence of dystrophic features in patients with type 1 neurofibromatosis and spinal deformities increase the risk of surgery? Spine (Phila Pa 1976) 38: 1595-1601.

24. Durrani AA, Crawford AH, Chouhdry SN, Saifuddin A, Morley TR (2000) Modulation of spinal deformities in patients with neurofibromatosis type 1. Spine (Phila Pa 1976) 25: 69-75.

25. Crawford AH (1994) Neurofibromatosis: The pediatric spine. Raven Press, New York.

26. Ogilvie JW (1995) Neurofibromatosis: Moe's textbook of scoliosis and other spinal deformities. (3rdedn), Saunders Company, Philadelphia.
27. Van Es S, North KN, McHugh K, De Silva M (1996) MRI findings in children with neurofibromatosis type 1: a prospective study. Pediatr Radiol 26: 478-487.

28. Johnson NS, Saal HM, Lovell AM, Schorry EK (1999) Social and emotional problems in children with neurofibromatosis type 1: evidence and proposed interventions. J Pediatr 134: 767-772.

29. Jacobsen FS, Crawford AH (1995) Complications in neurofibromatosis: Complications in pediatric orthopaedic surgery. JB Lippincott, Philadelpia.

30. Calvert PT, Edgar MA, Webb PJ (1989) Scoliosis in neurofibromatosis. The natural history with and without operation. J Bone Joint Surg Br 71: 246-251.

31. Sirois JL 3rd, Drennan JC (1990) Dystrophic spinal deformity in neurofibromatosis. J Pediatr Orthop 10: 522-526.

32. Buniatov RN (1983) [Clinical x-ray characteristics of scoliosis in neurofibromatosis]. Pediatriia : 49-51.

33. Winter RB (1984) Thoracic lordoscoliosis in neurofibromatosis: treatment by a Harrington rod with sublaminar wiring. Report of two cases. J Bone Joint Surg Am 66: 1102-1106.

34. Winter RB, Lonstein JE, Anderson M (1988) Neurofibromatosis hyperkyphosis: a review of 33 patients with kyphosis of 80 degrees or greater. J Spinal Disord 1: 39-49.

35. Ma J, Wu Z, Yang X, Xiao J (2011) Surgical treatment of severe cervical dystrophic kyphosis due to neurofibromatosis Type 1: a review of 8 cases. J Neurosurg Spine 14: 93-98.

36. Koptan W, ElMiligui Y (2010) Surgical correction of severe dystrophic neurofibromatosis scoliosis: an experience of 32 cases. Eur Spine J 19: 1569-1575.

37. Kawabata S, Watanabe $\mathrm{K}$, Hosogane N, Ishii K, Nakamura M, et al. (2013) Surgical correction of severe cervical kyphosis in patients with neurofibromatosis Type 1. J Neurosurg Spine 18: 274-279.

38. Halmai V, Domán I, de Jonge T, Illés T (2002) Surgical treatment of spinal deformities associated with neurofibromatosis type 1 . Report of 12 cases. J Neurosurg 97: 310-316.

39. Crawford AH (1989) Pitfalls of spinal deformities associated with neurofibromatosis in children. Clin Orthop Relat Res : 29-42.

40. Shen JX, Qiu GX, Wang YP, Zhao Y, Ye QB, et al. (2005) Surgical treatment of scoliosis caused by neurofibromatosis type 1. Chin Med Sci J 20: 88-92.

41. Wang Z, Liu Y (2010) Research update and recent developments in the management of scoliosis in neurofibromatosis type 1. Orthopedics 33 : 335-341.

42. Chizuo I, Hiroshi T, Satoshi I, Takashi N, Daisaku T (2012) Clinical Outcomes of Combined Anterior and Posterior Spinal Fusion for Dystrophic Thoracolumbar Spinal Deformities of Neurofibromatosis-1. Fate of Nonvascularized Anterior Fibular Strut Grafts. SPINE 38: 44-50.

43. Winter RB (2011) Severe neurofibromatosis kyphoscoliosis, posterior wedge osteotomy, halo-traction, and anterior autograft strut fusion, with 28-year follow-up. Spine (Phila Pa 1976) 36: E1774-1777.

44. Shahcheraghi GH, Tavakoli AR (2010) Corpectomy and circumferential spinal fusion in dystrophic neurofibromatous curves. J Child Orthop 4: 203-210.

45. Singh K, Samartzis D, An HS (2005) Neurofibromatosis type I with severe dystrophic kyphoscoliosis and its operative management via a simultaneous anterior-posterior approach: a case report and review of the literature. The Spine Journal 5: 461-466.

46. Parisini P, Di Silvestre M, Greggi T, Paderni S, Cervellati S, et al. (1999) Surgical correction of dystrophic spinal curves in neurofibromatosis. A review of 56 patients. Spine (Phila Pa 1976) 24: 2247-2253.

47. Sponseller P (2003) The spine in skeletal syndromes and dysplasias: Spinal deformities. The comprehensive text. Thieme, New York.

48. Curtis BH, Fisher RL, Butterfield WL, Saunders FP (1969) Neurofibromatosis with paraplegia. Report of eight cases. J Bone Joint Surg Am 51: 843-861. 
Citation: Park YS, Hyun SJ (2014) Spinal Deformity in Neurofibromatosis: Classification and Management. J Spine 3: 186. doi:

49. Lonstein JE, Winter RB, Moe JH, Bradford DS, Chou SN, et al. (1980) Neurologic deficits secondary to spinal deformity. A review of the literature and report of 43 cases. Spine (Phila Pa 1976) 5: 331-355.

50. Miller A (1936) NF-1 with reference to skeletal changes, compression myolitis and malignant degeneration. Arch Surg32: 109.

51. Stoker GE, Lenke LG, Dorward IG (2012) Posterior vertebral column resection for the treatment of dystrophic kyphosis associated with type-1 neurofibromatosis: a case report and review of the literature. Spine (Phila Pa 1976) 37: E1659-1664.

52. Hirschfeld SS, Rudner C, Nash CL Jr, Nussbaum E, Brower EM (1982) Incidence of mitral valve prolapse in adolescent scoliosis and thoracic hypokyphosis. Pediatrics 70: 451-454.

53. Cho SK, Stoker GE, Bridwell KH (2011) Spinal reconstruction with pedicle screw-based instrumentation and rhBMP-2 in patients with neurofibromatosis and severe dural ectasia and spinal deformity: report of two cases and a review of the literature. J Bone Joint Surg Am 93: e86.
54. Benglis D, Wang MY, Levi AD (2008) A comprehensive review of the safety profile of bone morphogenetic protein in spine surgery. Neurosurgery 62: ONS423-431.

55. Schouten ES, van de Pol AC, Schouten AN, Turner NM, Jansen NJ, et al. (2009) The effect of aprotinin, tranexamic acid, and aminocaproic acid on blood loss and use of blood products in major pediatric surgery: a meta-analysis. Pediatr Crit Care Med 10: 182-190.

56. Mesfin A, Buchowski JM, Zebala LP, Bakhsh WR, Aronson AB, et al. (2013) High-dose rhBMP-2 for adults: major and minor complications: a study of 502 spine cases. J Bone Joint Surg Am 95: 1546-1553.

57. Baldus CR, Bridwell KH, Lenke LG, Okubadejo GO (2010) Can we safely reduce blood loss during lumbar pedicle subtraction osteotomy procedures using tranexamic acid or aprotinin? A comparative 